\title{
Teaching Reform of "Electronic CAD and Electronic Assembly Practice" Based on Project Teaching Method
}

\author{
Xue Rui \\ Dept. electronic engineering department \\ North china institute of aerospace engineering \\ LangFang, China \\ xuerui9840@163.com
}

\author{
Cui Ruixue and Deng Zhiqing \\ Dept. electronic engineering department \\ North china institute of aerospace engineering \\ LangFang, China \\ cuiruixue2003@yahoo.com.cn
}

\begin{abstract}
According to the characteristic of "Electronic CAD and Electronic Assembly Practice" course, we adopted project teaching method for attempt practice teaching reform. The results show that project teaching can be realized seamless connection between personnel training and social needs, be achieved the objective of training the student collaborative innovation ability and promoting them engineering quality. Project teaching reform is vital to train practical and skilled talents for the career position under engineering education environment.
\end{abstract}

Keywords- project teaching method; practice teaching; engineering educationg

\section{INTRODUCTION}

With the development of society and electronic industrial technology, the wide application of pervasive computer, Application-oriented Undergraduate Universities should combine engineering practice to train practical and skilled talents under global CDIO (conceive, design, implement, operate) engineering education environment. Students should not only be grasp solid theoretical knowledge and skillfully use CAD (computer aided design), but also be have strong practical skills. We attempt to put teaching process in the specific situation of engineering, training solid professional foundation engineer through teamwork innovation and practice training which is described in $[1,2]$.

In the teaching process of "Electronic CAD and Electronic Assembly Practice” course, traditional teaching has many disadvantages in explaining of the theory and exercising on computer. So, it is must to actively seek effective teaching model reform. Through practice reform, project teaching can improve learning interest, train teamwork, train engineering innovation and the ability of solving practical problems.

\section{Project TEACHING Characteristics}

As the core of a typical project, project teaching method implements relevant teaching of teacher-led and studentcentered in specific items by analyzing the project into different stage, different module and different section. It can be in learning to do, learning by doing. Then, students not only grasp theoretical knowledge and improve the ability of practice, but also accumulate project experience and promote collaborative innovation capability.

\section{A. Preconditions}

Project teaching put the complete project into education activities through teachers and students. In order of achieving favorable teaching effect, the project implementation should satisfy some conditions, for example: showing component and electronic product, stimulating student's interest in study, integrating theory and Practice of the teaching content, designing the appropriate and layered project task, implementing illuminating and interactive teaching by student-centered.

\section{B. Advantages}

The philosophy of engineering education emphasizes the same of teaching process and engineering practice of environmental process which is mentioned in [3]. This course design teaching content on account of training engineering professional capacity. That is a complete product development and serial production process from designing printed circuit board (PCB) using Altium Disgner, to making electronic circuit board, to welding and debugging the product prototype.

\section{PRoJect TEACHING MEthoD}

With using project teaching method in teaching process, the lectures is designed into several projects, organizing and carrying out teaching based on the project which is mentioned in $[4,5,6]$. In order to the teaching aim of practice and focusing on the application, it needs students take part in the whole process of project, for improving the ability of solving practical problems and designing electronic product.

\section{A. The Selection of Project Task}

The selection of project task is the first step for project teaching method, is a crucial step to success of project teaching. The selection and develop must to meet the teaching requirements for personnel training on one hand and make up system comprehensive skill knowledge frame for students on the other. The instructor should to be put forward project task for the benefit of students mastering the skills and knowledge, that is interesting, suitable and gradual task. Because of students have study systematic knowledge of analog and digital electronic technology, making electric toys products become integrated project for learning this course by mastering the relevant theoretical knowledge. Not 
only is it knowledge consistency, but also it is improving interesting and practice capacity by achieving project task.

\section{B. The Distribution of Project Task}

The whole course divides into three classes about demonstration project, practice project and integrated project. Each class project includes five section tasks, for instance, project preparation, schematic diagram and simulation verification, designing PCB, making PCB and making product prototype, as illustrated in Fig.1. For each project task, it can be divided into several small tasks as follows.

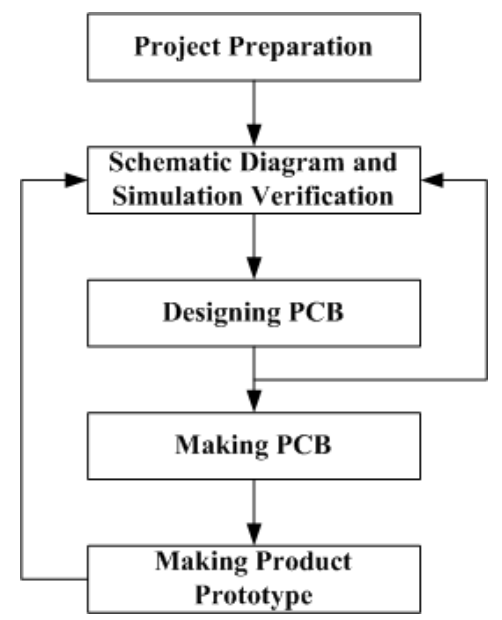

Figure 1. The Distribution of Project Task

Project preparation is divided into analyzing project task, partitioning circuit function and determining unit circuit. Schematic diagram and simulation verification is separated into designing schematic environment, operating schematic library, drawing schematic, electrical rule checking (ERC) and generation net-list, simulating verification circuit function. Designing PCB is divided into designing PCB environment, operating PCB library, PCB layout, PCB interactive route and design rule checking (DRC). Making PCB is separated into printing PCB negative, sticking sensitive layer, exposure, development, etching, releasing film and OSP. Making product prototype is divided into welding component, product assembly and debugging product performance.

With simulation verification, schematic diagram need to be revised until realizing the function of circuit. If finding schematic needs to be improved in PCB design process, designer should add or delete component in editing schematic. In making product prototype, it needs maybe to perfect schematic for meeting the actual demand and improving the circuit function. Thus, these small tasks are not isolated, that are interrelated, supplemented each other. The whole project task is implemented in organized and hierarchical state.

\section{The Implementation of Project Task}

In demonstration project, the instructor shows correct and error ways by simple circuit for students to be familiar with the design process of electronic product. In practice project, students must grasp the basic knowledge of designing and drawing circuit schematic form designing and making PCB to debugging simple circuit product, be trained the consciousness of standard drawing schematic and the skill of welding component. In integrated project, students should to be grasp hand-made layout and interactive rout in the specified frame size, hand-made PCB, circuit assembly and debugging by the difficult integrated project in order to training comprehensive ability in $[7,8]$.

The following example introduces the entire process of implementation project task thought "making electric toy product” integrated project.

1) Planning Scheme: That is project preparation, determining design scheme, specific circuit structure and each component parameters.

2) Identification Component: To know well component characteristics and encapsulation after buying them on component list.

3) Computer Aided Design: That is schematic diagram and simulation verification, designing PCB, which is building library and drawing schematic, drawing graphic symbol and component encapsulation, ERC with Altium Disgner. Then, the function of circuit is simulated and verified using Proteus or Multisim. Final, PCB is manual layout interactive route, DRC using Altium Disgner.

4) Manual Fabrication: To make PCB and product prototype, with photosensitive dry film technique to making PCB, welding component in hand-made PCB. Fig.2 shows the photosensitive dry film PCB of "making electric toy product”.

5) Project Inspection: To setting reasonable time node in project implementation process, examining each skill link. After finishing project task, that is to carry out checking product function, integrated theory, training report in order.

6) Self Evaluation: To self-assessment and mutual evaluation as a group, then, to develop mutual evaluation between groups.

7) Case Analysis: To analyze and summarize the gap of own work and good work, to put forward improvements.

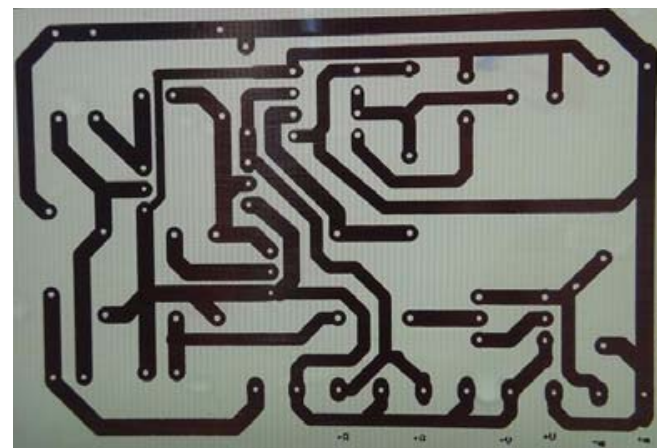

Figure 2. The Photosensitive Dry Film PCB of "making electric toy product” 


\section{The Reform Effect of Project Teaching}

Though designing education activities into project tasks, that encourage students rational using of learning resources, construct the network of gaining knowledge and skills, unfold collaborative interactive study, deliberate independently question and resolve it, exchange project results. Not only does it train professional knowledge and practical skills, but also does is supply the academic environment of cooperative innovation, try to acquiring knowledge and skills in independent and interactive learning.

With project teaching, it can evaluate objectively learning effect, find out the gap and own weaknesses in practice and innovation, in order to improving professional skill and engineering quality for afterwards. "Electronic CAD and Electronic Assembly Practice" course must to achieve better teaching effect if taking note of process control.

\section{CONCLUSION}

On the whole, the characteristics of project teaching is the students-centered and real project-based teaching method, for the aim of training students practice operant skill and teamwork. It combines education of knowledge with quality and ability. The instructor needs to have higher comprehensive quality. In order to promoting students independent thinking and improving the ability of solving practical problems, guidance of teacher must vary with each individual, grasp the scale, be just perfect.

Thus, though implementing the project-based teaching, this course can break the limit of knowledge system, take the integration teaching mode of theory and practice, be realize the zero distance of project and job.

\section{ACKNOWLEDGMENT}

This work is supported by the Key discipline of Hebei (Detection Technology and Automation Devices), the Key development discipline of Hebei (Signal and Information Processing) and the reform of teaching and research project foundation of North china institute of aerospace engineering (JY-2010-004-Y).

\section{REFERENCES}

[1] G.Anne,B.Jennifer,D.Christian and H.Victoria, “A Visibility Project: Learning to See How Preservice Teachers Take Up Culturally Responsive Pedagogy,” American Educational Research Journal, vol. 46, pp. 816-852, 2009.

[2] S. Newell,F. L. Edelman, "Developing a dynamic project learning and cross-project learning capability: synthesizing two perspectives,” Information Systems Journal, vol. 18, pp. 567-591.2008.

[3] C.Tan,Chan Yuen-Yan, "Knowledge Community: A KnowledgeBuilding System for Global Collaborative Project Learning," Proceedings of the IEEE, vol. 96, pp. 1049-1061,2008.

[4] Zhou aiqing,Kui xiuhui and Qu youtian,"Discussion on the Teaching Reform of Single-chip Computer Base on Mode CDIO at Vocational College,”ICCIT,pp. 2120-2123,2010.

[5] A. P.Fuller, R.J. Dainty and T.Thorpe, "Improving project learning: a new approach to lessons learnt,”International Journal of Managing Projects in Business, Vol.4,pp. 118-136,2011.

[6] Li HuiFang,Tang Yin, "Research on Personnel Training Model of Urban Rail Transit (URT) Information Management Major under Instruction of CDIO,” Energy Procedia, vol. 16, pp. 1300-1304, 2011.

[7] T. Kazuya, M. Akiyuki and M. Masakatsu,"Engineering Design Education through the CDIO Approach," J ournal of JSEE, vol. 60, pp. 1341-2167,2012.

[8] N. Hosseinzadeh, M. R. Hesamzadeh, “Application of Project-Based Learning (PBL) to the Teaching of Electrical Power Systems Engineering,"Education,IEEE Transactions on,Vol. 55, pp. 495501,2012 . 